\title{
POTRET PELAYANAN KESEHATAN SERTA LPAYA PENCEGAHAN DAN PENANGGULANGAN ATAS KEJADIAN STUNTING PADA BALITA DI DESA TERONG KECAMATAN DLINGO KABUPATEN BANTUL
}

\author{
Portrait of Health Service and Prevention and Treatment Efforts for Stunting on Toddlers in \\ Terong Village of Dlingo Subdistrict, Bantul District
}

\author{
Anastasia Nuniek Susetyowati \\ Balai Pelatihan Kesehatan (Bapelkes) Dinas Kesehatan \\ J1. Solo Km 12,5, Kalasan Yogya, Daerah Istimewa Yogyakarta \\ E-mail : anuniek a)gmail.com
}

Naskah diterima tanggal 31 Oktober 2019. Naskah direvisi tanggal 30 November 2019. Naskah disetujui tanggal 2 Desember 2019

\begin{abstract}
ABSTRAK
Salah satu tantangan yang dihadapi Pemerintah dalam penyiapan generasi yang sehtat, cerdas, produkitf, dan kuat adaiah permasaitahan suating. Desa Terong Kecamatan Dlingo Kabupaten Bantut di tahun 2019 ditetapkan sebagai salah lokus stunting oieh Tim Nasional Percepatan Penangguiangan Kemiskinan. Tujuan dalam penelitian ini adalah untuk melihat kondisi petayanan kesehatan ibu dan anak batita stunting serta upaya-upaya yang dilakukan dalam rangka pencegahan dan penanggulangan balita stunting di Desa Terong. Penelitian ini merupakan penelitian kualitatif dengsan pendekatan kasas pada populasi balita stunting di Desa Terong. Data primer dilakukan dengan instrumen kajian kejadian stunting pada balita di Desa Terong. sementara data sekunder berisi catutan-catatan hasil pelaksanaan kegiatan pemantanan pertumbuhan bulanan balita bulan Februari 2019. Data-data yang diperoleh kemudian dianalisa secara kualitatif deshriptif. Hasil penetitian memmiuktan bahwa stunting pada balita di Desa Terong dengan prevalensi 12,54 persen banyak terjadi pada usia 24 bulan ke atas. Intervensi yang dilakukan selama ini belum bisa meningkatkan status gizi balita. Pemantauan status gizi balita yang dilakukan rutin setiop bulan oleh kader di Posyandu tidak dapat mengidentifikasi kejadian stunting. Demikian juga dengan pelayanan

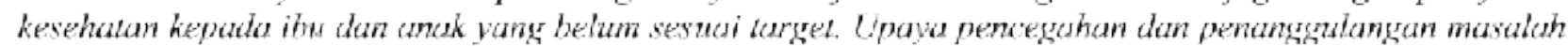
stunting pada baliza di Desa Terong belum optimal dan difokuskan pada masalah stunting.
\end{abstract}

Keywords: Status Gizi Balita, Kader Posyantu, Intervensi

\begin{abstract}
One of the challenges faced by the Government in preparing a healthy. smart, productive and strong generation is stunting problem. Terong Village, Diingo Subdistrict, Bantut Distict in 2019 was designated as one of the locus of stunting by National Team for Acceleration of Poverty Reduction. The purpose of this study is to portrait the condition of health services for maternal and stanting toddlers and its prevention and treatment efforts in Terong Village. The research is a qualizative research with a case approach to the population of stunting toddlers in Terong Village. The primary data was carried out with instruments for studying the incidence of sturiting in toddters under five in Terong Village, while secondary data contained records of the results of implementation of monthly toddler growth monitoring activities in February 2019. The data obtained were then analyzed in a descriptive qualitative method. The results showed that stanting in toddlers in Terong Village with a prevalence of 12.54 percent occurred at the age of 24 months and over. The interventions carried out so far have not heen able to improve the nutritional status of toddlers. The monitoring of the nutritional status of foddlers under five that is carried out routinely every month by cadres in the Posyandu cannot identify stunting events. T.ikewise, heaith services for mothers and children who are not yet on target. Efforis to prevent and overcome stunting problems in toddlers in Terong Village are not optimat and not focused on stunting problems.
\end{abstract}

Keywords: Toddler Nutrition Status, Cadre Posyandu, Intervention 


\section{PENDAHULUAN}

Salah satu visi besar pemerintah adalah penciptaan SDM yang unggul. Salah satu terjemahan visi besar tersebut adalah penyiapan generasi yang sehat, cerdas, produktil, dan kuat. Masih banyak tantangan yang dihadapi dalam penyiapan generasi yang schat, cerdas, produktil, dan kual tersebul. Salah salu tantanganıya adalah permasalahan stunting.

Stunting adelah suatu kondisi balita yang memiliki panjang atau tinggi badan kurang jika dibandingkan dengan umurnya menurut standar pertumbuhan anak dari WIIO. Masalah stunting bukan semata pada ukuran fisik pendek tetapi lebih pada konsep bahwa proses terjadinya stunting bersamaan dengan proses terjadinya hambatan pertumbuhan dan perkembangan organ lainnya termasuk otak. Artinya, seorang anak yang menderita stunting kenungkinan besar juga mengalami hambatan pertumbuhan dan perkembangan organ lainnya (lzwardy, 2016). Kementerian Perencanaan dan Pembangunan Nasional' Badan Perencanaan dan Pembangunan Nasional dalam Pedoman Pelaksanaan Intervensi Penurunan Stunting (2018) menuliskan bahwa masalah gizi lain terkait dengan stunting yang masih menjadi masalah keschatan masyarakat adalah anemia pada ibu hamil $(48,9 \%)$, Berat Bayi Lahir Rendah atau BBLR $(6,2 \%)$, balita kurus atau wasting $(10,2 \%)$ dan anemia pada balita.

Kementerian Kesehatan (2018) dan Kemenko Bidang Pembangunan dan Kebudayaan (2018) dalam sumber yang berbeda menyebutkan bahwa stunting discbabkan olch banyak faktor dan dapat mengakibatkan dampak buruk pada penderitanya yaitu rentan terhadap penyakit dan berisiko mengidap penyakil degenerative ketika berusia dewasa. Balita stunting di masa mendatang akan mengalami kesulitan dalam mencapai perkembangan fisik dan kognitif yang optimal. Hasil riset Bank Dunia (dalam Kemendes Pembangunan Dacrah Tertinggal dan Transmigrasi, 2017) menggambarkan kerugian akibat stunting mencapai $3 \quad 11 \%$ dari pendapatan Domestik Bruto (PDB). Dengan nilai PDB 2015 sebesar Rp 11.000 Triliun, kerugian ekonomi akibat stunting di Indonesia diperkirakan mencapai $\mathrm{Rp} 300$ Triliun - Rp 1.210 Triliun per tahun. Gambar di bawah memperjelas dampak stunting terhadap kualitas sumber daya manusia.

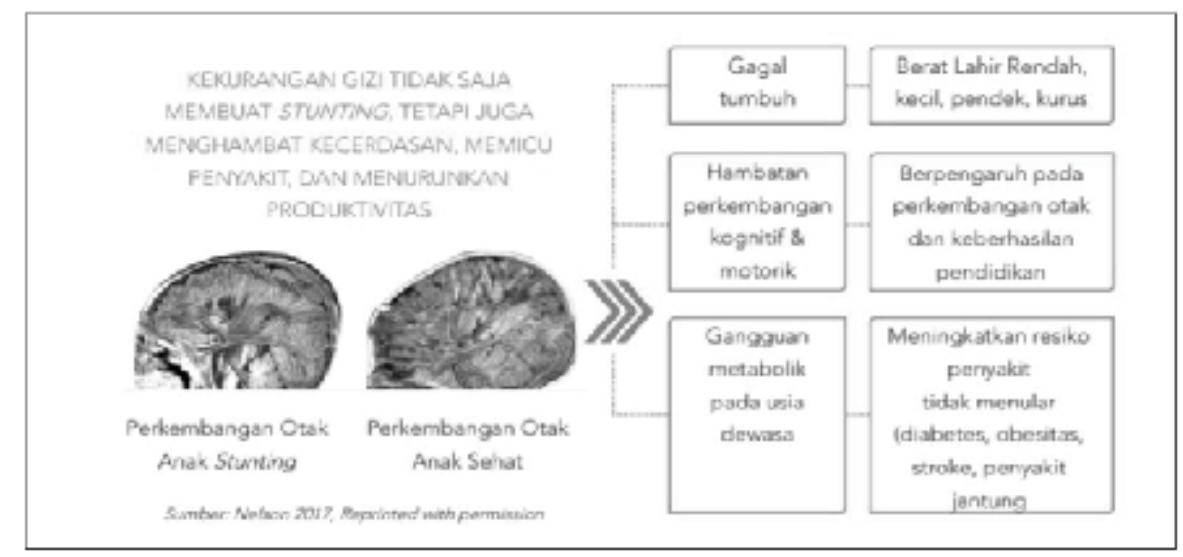

(Sumber : Kementerian Perencanaan dan Pembangunan Nasionali Badan Perencanaan dan Pembangunan Nasional, 2018)

Gambar 1. Dampak Stunting terhadap Kualitas Sumber Daya Manusia

Prevalensi stunting selama 10 tahun terakhir menunjukkan tidak adanya perubahan yang signifikan dan ini mempertegas mendesaknya penanganan stunting dengan segera. Hasil Riset Kesehatan Dasar
(Riskesdas) 2018 menunjukkan 30,8\% atau sekitar 7 juta balita menderita stunting. Menurut batasan WHO $(20)$ Indonesia masih termasuk negara yang mempunyai masalah gizi. Lebih dari $1 / 3$ anak berusia di bawah 5 (lima) tahun di Indonesia tingginya berada di bawah rata-rata. Dengan angka ini Indonesia tercatal sebagai 
negara peringkat kelima di dunia dengan angka kasus stunting terbanyak. Dengan jumlah $30,8 \%$, Indonesia hanya sedikit lebih baik dari Kamboja $41 \%$, Laos $44 \%$, Timor Leste $58 \%$, yang mengalami masalah stunting di kawasan Asia Tenggara.

Stunting bisa dideteksi sejak lahir dan selama masa pertumbuhan balita dengan melakukan pengukuran status gizi secara anthropometri. Stunting pada balita bisa dicegah dan diantisipasi dengan pemberian pelayanan kesehatan melalui pendekatan siklus kehidupan mulai dari remaja putri sebagai calon ibu, ibu hamil dengan janinnya, ibu menyusui, bayi hingga usia balita, namun kenyataan di masyarakat masih banyak ditemukan balita yang menderita stunting (Lwardy, 2019).

Pemerintah telah menetapkan stunting sebagai salah satu program prioritas. Desa Terong Kecamatan Dlingo Kabupaten Bantul di tahun 2019 ditctapkan scbagai salah lokus stunting oleh Tim Nasional Percepatan Penanggulangan Kemiskinan. Lokus stunting adalah desa yang menjadi prioritas untuk intervensi penanganan stunting. Pemilihan Desa Terong menjadi lokus stunting tidak terlepas dari kegiatan pemantauan status gizi balita di hulan Februari 2019 di Desa Terong Kecamatan Dlingo Kabupaten Bantul. Pada kegiatan tersebut ditemukan sebanyak 44 anak atau $12,54 \%$ yang menderita stunting. 75 persen stunting diderita oleh balita kelompok usia di atas 24 bulan. Balita stunting di Desa Terong sebagian besar berusia di atas 24 bulan yang berarti sudah melampaui masa kritis windows of opportunity, artinya dampak pertumbuhan dapat bersifat permanen. Balita stunting Desa Terong akan tumbuh menjadi dewasa yang pendek.

Berdasarkan kondisi stunting di atas, penulis tertarik untuk melihat potret pelayanan kesehatan ibu dan anak balita stunting dan upaya-upaya yang telah dilakukan dalam rangka pencegahan dan penanggulangan balita stunting di Desa Terong Kecamatan Dlingo Kabupaten Bantul.

\section{Rumusan Masalah}

Bcrdasarkan latar bclakang di atas maka rumusan masalah dalam penelitian ini adalah:

1. Bagaimana potret pelayanan keschatan ibu dan anak balita stunting di Desa Terong Kecamatan Dlingo Kabupaten Bantul?

2. Upaya apa yang telah dilakukan dalam rangka pencegahan dan penanggulangan balita stunting di Desa Terong Kecamatan Dlingo Kabupaten Bantul?

\section{Tujuan dan Manfaat Penelitian}

Tujuan dalam penelitian ini adalah untuk melihat kondisi pelayanan keschatan ibu dan anak balita stunting serta upaya-upaya yang telah dilakukan dalam rangka pencegahan dan penanggulangan balita stunting di Desa Terong Kecamatan Dlingo Kabupaten Bantul. Hasil penelitian ini diharapkan dapat dijadikan dasar masukan alau rekomendasi kepada pelayanan kesehatan wilayah, puskesmas dan jaringannya di wilayah penclitian baik di lingkup Pemerintah Desa Terong, Pemerintah Kecamatan Dlingo, dan Pemerintah Kabupaten Bantul terkait apa yang belum dan telah dilakukan sesuai dengan prosedur.

\section{TIN.IAUAN PLSTAKA \\ Stunting}

Stunting discbabkan olch banyak faktor antara lain kondisi sosial ekonomi, kondisi kesehatan dan gizi ibu yang kurang baik saat hamil serta setclah persalinan, postur tubuh ibu yang pendek, jarak kehamilan yang terlalu dekat, usia ibu yang masih terlalu muda serta asupan gizi yang kurang pada saat hamil, kesakitan pada bayi, dan kurangnya asupan gizi pada bayi. Kondisi ibu sebelum kehamilan yaitu berat badan, tinggi badan, dan status gizinya merupakan faktor yang dapat mempengaruhi terjadinya stunting. Apabila status gizi remaja putri calon ibu tidak diperbaiki dapat berdampak pada meningkatnya prevalensi balita stunting di Indonesia (Direktorat Kesehatan dan Gizi Masyarakat dan Sekretariat Percepatan Perhaikan GiziBappenas, 2018). Selain itu, dalam Buku Saku Kementerian Desa Daerah Tertinggal dan Transmigrasi (2017), stunting juga dapat discbabkan karena praktik pengasuhan yang tidak baik, terbatasnya layanan kesehatan pada 
Antenatal Care ( $A N C$ ), Post Natal atau masa nifas, pembelajaran dini yang berkualitas, kurangnya akses makanan yang bergizi, kurangnya akses air bersih dan sanitasi.

Saputra (2012) dalam penelitiannya menyatakan bahwa ada dua penyebab langsung masalah gizi, yaitu kurangnya asupan makanan dan adanya penyakit infeksi yang keduanya saling mempengaruhi secara timbal balik. Permasalahan gizi kurang tersebut merupakan implikasi lemahnya sistem pelayanan keschatan, pola asuh orang tua yang kurang memberikan perhatian dalam lumbuh kembangnya, dan stok atau persediaan makanan dalam rumah tangga. Semua itu karena persoalan kemiskinan, rendahnya Pendidikan masyarakat, dan kurang terampilnya masyarakat dalam menjalani kehidupan (life skill).

\section{Pelayanan Kesehatan dalam Upaya Pencegahan dan Penanggulangan Stunting}

Stunting merupakan manifestasi dari kegagalan pertumbuhan yang dimulai sejak dalam kandungan hingga anak berusia dua tahun. Sugiantono (2018) menyatakan bahwa pencegahan dan penanggulangan stunting harus dimulai secara tepat sebelum kelahiran dan berlanjut sampai anak berusia dua tahun. Intervensi yang paling menentukan adalah mempersiapkan seorang calon ibu, memberikan pelayanan kepada ibu hamil secara maksimal dan memastikan persalinan dilakukan di fasilitas pelayanan kesehatan, pemberian ASI Eksklusif yang diawali dengan inisiasi menyusu dini (IMD) dan melakukan pemantauan pertumbuhan perkembangan anak secara terus menerus oleh tenaga kesehatan pada 1000 hari pertama kehidupan (HPK).

Berdasarkan Peraluran Menteri Kesehatan Nomor 97 Tahun 2014 tentang Pelayanan Keschatan Masa Scbelum Hamil, Masa hamil, Persalinan, dan Masa Sesudah Melahirkan, serta Nomor 25 Tahun 2014 tentang Upaya Keschatan Anak, pelayanan keschatan yang diberikan dalam tahapan siklus kehidupan antara lain pelayanan kesehatan pada masa sebelum hamil, masa hamil (ibu hamil), persalinan, dan masa sesudah melahirkan, dan pelayanan keschatan anak mulai dari janin dalam kandungan, bayi baru lahir, bayi, anak balita dan prasekolah, anak usia sekolah dan remaja.

Pelayanan kesehatan masa sebelum hamil adalah setiap kegiatan dan/atau serangkaian kegiatan yang ditujukan pada perempuan sejak saat remaja hingga saat sebelum hamil dalam rangka menyiapkan perempuan menjadi hamil sehat. Pelayanan ini dilakukan pada remaja, calon pengantin dan atau pasangan usia subur untuk mempersiapkan perempuan dalam menjalani kehamilan dan persalinan yang sehat dan selamat serta memperoleh bayi yang sehat. Pelayanan kesehatan yang diberikan meliputi pemeriksaan fisik (tanda vital dan status gizi), pemeriksaan penunjang, pemberian imunisasi, suplemen gizi, konsultasi kesehatan dan pelayanan kesehatan lainnya.

Pelayanan kesehatan masa hamil (ibu hamil) adalah setiap kegiatan dan/atau serangkaian kegiatan yang dilakukan sejak terjadinya masa konsepsi hingga melahirkan. Pelayanan keschatan masa hamil ini bertujuan untuk memenuhi hak setiap ibu hamil memperoleh pelayanan kesehatan yang berkualitas sehingga mampu menjalani kehamilan dengan sehat, bersalin dengan sclamat dan melahirkan bayi schat dan berkualitas.

Pelayanan kesehatan masa melahirkan (masa persalinan) adalah sctiap kegiatan dan/atau serangkaian kegiatan yang ditujukan pada ibu sejak dimulainya persalinan hingga 6 (enam) jam sesudah melahirkan. Persalinan harus dilakukan di fasilitas pelayanan kesehatan dengan standar Asuhan Persalinan Normal (AI'N). Pelayanan yang diberikan meliputi membuat keputusan klinik; asuhan sayang ibu dan sayang bayi; pencegahan infeksi; pencatatan asuhan persalinan; dan rujukan pada kasus komplikasi ibu dan bayi lahir.

Pelayanan kesehatan masa sesudah melahirkan adalah setiap kegiatan dan/atau scrangkaian kegiatan yang dilakukan ditujukan pada ibu selama masa nifas dan pelayanan yang mendukung bayi yang dilahirkannya sampai berusia 2 (dua) tahun. Pelayanan ini meliputi pelayanan kesehatan bagi ibu dan bagi bayi baru lahir. Pelayanan kesehatan ibu paling sedikit 3 (tiga) kali selama masa nilas dengan 
ketentuan 1 (satu) kali pada periode 6 (enam) jam sampai dengan 3 (tiga) hari pasca persalinan; 1 (satu) kali pada periode 4 (empat) hari sampai dengan 28 (duapuluh delapan) hari pasca persalinan; dan 1 (satu) kali pada periode 29 (dua puluh Sembilan) hari sampai 42 (empat puluh dua) hari pasca persalinan. Pelayanan kesehatan bayi baru lahir dilaksanakan sesuai dengan ketentuan perundang-undangan yang berlaku.

Masih dalam Peraturan Menteri Kesehatan Nomor 97 Tahun 2014 tentang Pelayanan Kesehatan Masa Sebelum Hamil, Masa hamil, Persalinan, dan Masa Sesudah Melahirkan, serta Nomor 25 Tahun 2014 tentang Upaya Kesehatan Anak, pelayanan kesehatan bayi baru lahir termasuk dalam upaya kesehatan anak (mulai janin sampai usia 18 tahun) adalah kegiatan dan/atau serangkaian kegiatan yang dilakukan secara terpadu, terintegrasi dan berkesinambungan untuk memelihara dan meningkatkan derajat kesehatan anak dalam bentuk pencegahan penyakit, pengobatan penyakit, dan pemulihan kesehatan oleh pemerintah, pemerintah daerah dan/atau masyarakat. Bayi baru lahir yang dimaksud adalah bayi umur 0 sampai dengan 28 hari. Pelayanan kesehatan dilaksanakan melalui pelayanan kesehatan neonatal esensial; skrining Bayi Baru Lahir; dan pemberian komunikasi, informasi, edukasi kepada ibu dan keluarganya. Pelayanan kesehatan neonatal wajib diberikan pada saat lahir 0 (nol) sampai 6 (enam) jam dan setelah lahir 6 (enam) jam sampai 28 (dua puluh delapan) hari sebanyak paling sedikit 3 (tiga) kali yaitu 1(satu) kali pada umur $6-48$ jam; 1 (satu) kali pada umur $3-7$ hari; dan 1 (satu) kali pada umur $8-28$ hari.

Pelayanan kesehatan Bayi Umur 0 11 bulan), Anak Balita (umur 12 - 59 bulan) dan Prasekolah (umur $60-72$ bulan) ditujukan untuk meningkatkan kelangsungan dan kualitas hidup Bayi, Anak Balita dan Prasekolah. Pelayanan kesehatan tersebut dilakukan melalui pemberian ASI Eksklusif pada bayi hingga usia 6 bulan, pemberian ASI hingga 2 (dua) tahun, pemberian makanan pendamping ASI (MPASI) mulai usia 6 (enam) bulan, pemberian imunisasi dasar lengkap bagi Bayi, pemberian imunisasi lanjutan pada anak usia 18 bulan dan
24 bulan, pemberian Vitamin $\Lambda$, upaya pola mengasuh anak, pemantauan pertumbuhan dan perkembangan, pemantauan gangguan tumbuh kembang, manajemen terpadu balita sakit, dan merujuk kasus.

\section{METODOLOGI PENELITIAN}

Pendekatan penelitian yang digunakan adalah penelitian kualitatif dengan pendekatan kasus pada populasi balita stunting di Desa Terong Kecamatan Dlingo Kabupaten Bantul. Sifat penelitian adalah deskriptif dilakukan dengan pendekatan cross-sectional yaitu untuk menggambarkan kegiatan pelayanan kesehatan dan perbaikan gizi pada ibu dan balita stunting pada waktu yang sama. Data yang digunakan adalah data primer dan data sekunder. Data primer dilakukan dengan instrumen kajian kcjadian stunting pada balita di Desa Tcrong Kecamatan Dlingo Kabupaten Bantul, sementara data sekunder dalam penelitian ini adalah dokumen yang berisi catatan-catatan hasil pelaksanaan kegiatan pemantauan pertumbuhan bulanan balita kegiatan Pemantauan Status Gizi bulan Februari 2019.

Data-data yang diperoleh dalam penelitian kemudian dianalisa secara kualitatif deskriptif guna memberikan gambaran lentang kesesuaian pelayanan kesehatan pada ibu dan anak balita stunting dengan standar pelayanan keschatan 1000 HPK dan tahapan siklus kehidupan manusia (life cycle). Hasil analisis ini akan dijadikan sebagai dasar memberikan masukan atau rekomendasi kepada pelayan kesehatan wilayah, puskesmas dan jaringannya di wilayah penelitian.

HASIL DAN PEMBAHASAN PENELITLAN 1. Ilasil Penelitian

A. Potret Pelayanan Kesehatan Ibu dan Anak Balita Stunting Di Desa Terong Kecamatan Dlingo Kabupaten Bantul

Pelayanan kesehatan ibu dan anak yang dilakukan Puskesmas Dlingo II sebagai pembina kesehatan wilayah Desa Terong yang tertuang dalam Rencana Kegialan Anggaran (RKA) Puskesmas Dlingo II Tahun 2019 mencakup pelayanan keschatan ibu, keschatan neonatus dan bayi, kesehatan balita dan anak prasekolah 
dan pelayanan gizi. Berdasarkan rencana kegiatan tersebut, hasil penelitian ini membagi temuan pelayanan kedalam tiga tahap: 1) Pelayanan kesehatan masa hamil, 2) Pelayanan kesehatan masa melahirkan, dan 3) Pelayanan kesehatan masa sesudah melahirkan.

1) Pelayanan Kesehatin Masa Hamil Pelayanan kesehatan masa hamil (ibu hamil) adalah setiap kegiatan dan/atau serangkaian kegiatan yang dilakukan sejak terjadinya masa konsepsi hingga melahirkan. Kegiatan pelayanan kesehatan di tahap ini yang ditujukan kepada ibu hamil dilakukan setiap bulan sekali yang terdiri dari pendataan ibu hamil, pemantauan ibu hamil berisiko, dan temu ibu hamil setahun sekali.

Berdasarkan hasil pengumpulan data riwayat pelayanan kesehatan yang pernah diterima oleh ibu dan anak balita stunting, sebagian besar ibu balita stunting saat hamil melakukan kunjungan ibu hamil K1 sampai K4 dan mendapatkan suplemen tablet tambah darah, mendapatkan promosi dan konseling gizi seimbang ibu hamil sesuai ketentuan, namun tidak mendapatkan PMT (pemberian makanan tambahan) ibu hamil

\section{2) Pelayanan Kesehatan Masa Melahirkan}

Pelayanan keschatan masa melahirkan (masa persalinan) adalah setiap kegiatan dan/atau serangkaian kegiatan yang ditujukan pada ibu sejak dimulainya persalinan hingga 6 (enam) jam sesudah melahirkan. Kegiatan pelayanan kesehatan pada tahap ini meliputi pendataan ibu bersalin serta menjalankan proses persalinan. Pada saat persalinan, semua ibu balita stunting ditolong oleh tenaga kesehatan bidan atau dokter.

3) Pelayanan Kesehatan Masa Scsudah Mclahirkan
Pelayanan kesehatan masa sesudah melahirkan adalah setiap kegiatan dan/atau serangkaian kegiatan yang dilakukan ditujukan pada ibu selama masa nifas dan pelayanan yang mendukung bayi yang dilahirkannya sampai berusia 2 (dua) tahun. Pelayanan keschatan yang dilakukan di tahap ini adalah pemantauan kesehatan ibu nifas, pelayanan neonatus, pelayanan balita, dan pelayanan kesehatan anak prasekolah.

Pemantauan kesehatan ibu nifas dilakukan setiap bulan sekali. Sebagian besar ibu melahirkan sudah melakukan kunjungan ibu nifas yang pertama (KFl), mendapatkan suplemen vitamin A dan mendapatkan promosi serta konseling gizi seimbang sesuai ketentuan. Kunjungan yang dilakukan ibu nifas hanya pada kunjungan pertama. Pada kunjungan kedua dan ketiga ibu nifas tak pernah lagi melakukan kunjungan.

Kegiatan pelayanan kesehatan kepada neonalus yang dilakukan berupa pemantauan kesehatan neonatus risiko tinggi sctiap bulan sckali. Hampir sernua balita stunting sad bayi neonatal (0-28 hari) sudah melakukan kunjungan neonatal pertama (KN1), mendapatkan peyanan kesehatan IMD (Inisiasi Menyusu Dini), Vitamin K dan Imunisasi $\mathrm{Hb} 0$ sesuai ketentuan, namun tidak melakukan KN2 dan KN3 yang scharusnya dilakukan.

Setiap bulan tenaga kesehatan memantau pertumbuhan status gizi semua balita stunting, walau ada yang belum rutin. Selain itu balita stunting mendapat vitamin A setiap bulan Februari dan Agustus, mendapat imunisasi dasar lengkap, promosi dan konseling gizi seimbang. Sebagian besar bayi neonalus hingga balita stunting sudah memanfaatkan dan mendapatkan pelayanan keschatan yang sesuai di puskesmas, Posyandu, 
Bidan Praktik, Dokter Praktik dan fasilitas pelayanan keschatan lainnya

Dari semua balita stunting, hanya satu balita yang mendapatkan ASI Eksklusif: ASI merupakan kebutuhan dasar bayi yang memegang peranan penting bagi kesehatan dan mempertahankan kelangsungan hidup bayi terutama usia $0-6$ bulan. ASI adalah makanan bayi yang paling sempuma banyak mengandung komponen yang berperan dalam sistem pertahanan tubuh juga dalam perkembangan jaringan organ. Adanya zat kekebalan dalam ASI dapat menghindarkan bayi dari penyakil. Strategi Nasional Peningkatan Pcmberian ASI (Departemen Kesehatan, 2001) telah menegaskan bahwa pemberian ASI Eksklusif sejak lahir hingga usia 6 bulan dapat menurunkan kesakitan bayi sebesar 10 20 kali dan kematian sebesar 1-7 kali.

Terkait pemberian makanan tambahan (PMT) balita, semua balita stunting tidak mendapat PMT balita maupun forlifikasi zal besi alau suplemen lain. Meski demikian, berdasarkan hasil pemantauan status gizi vang dilakukan dengan mengukur berat badan balita stunting diketahui diantara 36 anak yang teridentifikasi stunting di Desa Terong terdapat 27 anak $(75 \%)$ yang status gizinya masih lermasuk kategori baik.

\section{Pcngukuran berat badan balita dilakukan secara rutin. Hasil pengukuran tersebut menunjukkan bahwa kegiatan pemantauan status gizi yang dilakukan kader dengan mengukur berat badan balita setiap bulan tidak bisa digunakan untuk mengidentifikasi kejadian stunting, karena stunting hanya bisa diketahui dengan mengukur tinggi badan atau panjang badan anak. Pemantauan status gizi dengan mengukur tinggi badan sclama ini hanya dilakukan oleh tenaga kesehatan terlatih sebanyak 2}

kali setiap tahun, waktunya bersamaan dengan pemberian vitamin A balita yaitu bulan Februari dan Agustus.

Pemantauan status gizi selama ini dilakukan oleh kader. Kader memiliki peran penting dalam pelaksanaan posyandu yang bertujuan untuk meningkatkan derajat kesehatan ibu, anak dan masyarakat secara umum. Selama ini pembinaan Posyandu Balita dilakukan setiap bulan sekali. Kader Posyandu yang sudah secara rutin melaksanaan pemantauan dengan mengukur berat badan sebaiknya juga dilatih agat mampu melakukan pengukuran tinggi badan secara rutin.

Pemantauan kesehatan bayi berupa stimulasi, deteksi dan intervensi dini tumbuh kembang (SDIDTK) dilakukan setiap 6 bulan sekali. Pemantauan yang hanya 6 bulan sekali menunjukkan bahwa memang balita tidak terdeteksi tumbuh kembangnya setiap bulan. Hal ini terlihat dari hasil pengamatan grafik garis pertumbuhan balita yang terputus-putus menunjukkan bahwa balita tidak rutin mclakukan penimbangan. Selain garis pertumbuhan, terlihat juga status gizi yang semakin mengarah ke kategori gizi kurang bahkan buruk.

Balita stunting dengan usia dibawah 1 tahun, perubahan arah garis pertumbuhannya terjadi lebih cepat dibandingkan usia $1-2$ tahun, dan perubahan arah usia 1 - 2 tahun terjadi lebih cepat dibandingkan usia di atas 2 tahun. Perubahan arah garis pertumbuhan menuju stunting padia balita yang lahir tahun 2019 mulai terjadi di usia 3 bulan, sementara yang lahir tahun 2018 mulai terjadi di usia 5 atau 6 bulan, dan yang lahir tahun 2017 ke bawah mulai terjadi di usia 6 atau 7 bulan. Kondisi tersebut dapat tcrjadi karcna cadangan gizi anak selama dalam kandungan semakin sedikit bahkan kurang, asupan gizi pasca lahir semakin sedikit atau ada 
gangguan kesehatan yang semakin berat dari tahun ke tahun.

Grafik garis pertumbuhan status gizi yang semakin mengarah ke kategori gizi kurang bahkan buruk juga menggambarkan bahwa upaya intervensi yang dilakukan selama ini belum mampu memulihkan atau meningkatkan status gizi balita menjadi baik atau normal. Salah satu upaya yang dilakukan tenaga kesehatan selain SDIDTK setiap 6 bulan sekali adalah melakukan pendampingan terhadap balita kurus.

Kegiatan pelayanan kesehatan anak prasekolah terdiri dari pemantauan kesehatan dan gizi setiap 6 bulan, pemantauan tinggi dan berat badan anak baru sekolah, dan pemantauan garam beryodium. Kegiatan yang dilakukan setiap bulan sckali berupa pelacakan gizi buruk dan pemberian makanan tambahan (PMT) penyuluhan.

\section{B. Upaya Pencegahan dan Penanggulangan Balita Stunting \\ Puskesmas menurut Permenkes 75} tahun 2014 mempunyai tanggungjawab menyehatkan suatu wilayah yang didalamnya ada individu, keluarga dan agregat penduduk dengan nilai budayanya. Upaya mencegah dan mengatasi masalah stunting di Desa Terong menjadi tanggungjawab Puskesmas Dlingo II sebagai pembina kesehatan wilayah, namun kegiatan yang akan dilakukan harus dikoordinasikan dan diurus oleh Desa. Desa menjadi tumpuan pemerintah dalam upaya menekan angka stunting. Generasi schat dan ecrdas di desa menjadi penopang generasi emas dimasa mendatang. (Kemendes Pembangunan Daerah Tertinggal, dan Transmigrasi, 2017). Upaya pelayanan kesehatan yang direncanakan oleh Puskesmas Dlingo II dan bantuan anggaran dari Pemerintah Desa Terong belum ditujukan pada upaya pencegahan dan penanggulangan masalah stunting. Kegiatan yang dilakukan belum sesuai program Pemerintah Indonesia yang ada dalam Buku Saku Desa dalam Penanganan Stunting (2017) dan Buku 100) Kabupaten'Kota Prioritas Untuk Intervensi Anak Kerdil (Stunting) (2017) yang berisi penjelasan tentang bagaimana menangani stunting melalui intervensi spesifik dan intervensi sensitive pada sasaran $1000 \mathrm{HPK}$ sampai anak usia 6 tahun.

Selama ini updaing data balita stunting dilakukan setiap tahun sekali. Pasca ditetapkannya Desa Terong sebagai lokus stunting, Puskesmas segera menindaklanjuti dengan membuka kelas ibu, melakukan pemeriksaan balita stunting dengan mendatangkan dokter spesialis anak, pemberian makanan bayi dan anak (PMBA), dan melakukan skrining balita setiap tiga bulan sekali.

Perlemuan pembinaan Kader Posyandu di Puskesmas Dlingo II pada bulan Mei 2019 dan pertemuan advokasi kegiatan Komunikusi Perubahan Perilaku di Kantor Desa Terong bulan Juli 2019, Kepala Desa Terong akan memberikan dukungan penuh pada upaya-upaya untuk mengatasi permasalahan keschatan di wilayah desanya melalui pernyataan yang disampaikan. Kepala Desa Terong berjanji akan mengalokasi dana dari Anggaran Dana Desa yang dikoordinasikan dengan tenaga kesehatan pembina wilayah desa. Setiap bulan ada bantuan anggaran dari desa untuk kegiatan Posyandu sebesar lima ribu rupiah sampai tujuh tibu rupiah per anak.

\section{Pembahasan}

Undang-Undang Perlindungan Anak Nomor 23 Tahun 2002 telah menegaskan bahwa setiap anak berhak untuk hidup, tumbuh, berkembang dan berpartisipasi secara wajar, mendapat perlindungan dari kekerasan dan diskriminasi. Mereka juga berhak memperoleh pelayanan kesehatan dan jaminan sosial sesuai dengan kebutuhan fisik, mental, spiritual dan sosial. Semua pihak mempunyai peran dalam menciptakan lingkungan yang kondusif supaya anak dapat mengembangkan potensi yang 
dimilikinya sehingga menjadi generasi berkualitas. Sama seperti anak di belahan dunia lainnya, anak di Desa Terong pun berhak untuk tumbuh sehat baik fisik, mental, spiritual dan sosial.

Hasil penelitian menunjukkan bahwa Desa Terong selama ini belum optimal dalam memberikan pelayanan sekaligus meminimalkan terjadinya kasus stunting. Pemantauan status gizi balita dengan mengukur tinggi badan hanya dilakukan dua kali setahun. Hal ini menjadi salah satu penyebab lambatnya kejadian stunting diketahui. Padahal kejadian stunting dapat diketahui lebih awal apabila pemantauan pertumbuhan balita dengan mengukur tinggi atau panjang badan dilakukan secara rutin setiap bulan sejak awal kelahiran. Pcmantauan dilakukan scbagai upaya pencegahan, terutama pada balita usia $0-2$ tahun yang masih berada di periode emas 1000 HPK. Bila ada masalah pertumbuhan dan kesehatan dapat segera diketahui dan diintervensi sehingga tidak berlanjut berkembang menjadi stunting.

Upaya pencegahan dan penanggulangan balita stunting bukan hanya menjadi tugas dan tanggung jawab tenaga kesehatan, melainkan juga keaktifan dan peran serta masyarakat. Tidak rutinnya melakukan penimbangan di Posyandu menggambarkan masyarakat juga kurang aktif mengikuti kegiatan pemantauan status gizi balita. Perlu upaya dari pembina wilayah kesehatan guna meningkatkan peran serta masyarakat agar semua balita dapat terpantau terus-menerus. Lpaya tersebul dilakukan untuk antisipasi bila terjadi pcrmasalahan hambatan pcrtumbuhan dan kesehatan dapat segera diketahui dan diintervensi sehingga tidak berlanjut berkembang menjadi stunting yang akan lebih sulit memulihkannya.

Grafik garis pertumbuhan status gizi yang semakin mengarah ke kategori gizi kurang bahkan buruk juga menggambarkan bahwa upaya intervensi yang dilakukan selama ini belum mampu alau minimal memulihkan alau meningkatkan status gizi balita menjadi baik atau normal. Berbagai Kebijakan tentang penanganan permasalahan pangan dan gizi sudah lama dibuat antara lain oleh Presiden RI, Kemenkes RI, Kemendagri, Kementerian Desa. Pedoman dan petunjuk teknis untuk melakukan pencegahan dan mengatasi masalah gizi buruk dan stunting juga sudah diterbitkan, antara lain Petunjuk Teknis Tata Laksana Anak Gizi Buruk, Kerangka Kebijakan Gerakan 1000 HPK, serta Buku Saku Desa dalam Penanganan Stunting, Pedoman Pencegahan dan Tatalaksana Gizi Buruk pada Balita. Semuanya itu dapat digunakan sebagai acuan pelaksanaan kegiatan.

Tbu balita sturting saat hamil sudah memanfaatkan layanan kesehatan dan sebagian besar sudah mendapatkan pelayanan yang sesuai, tetapi tidak mendapatkan PWT ibu hamil. Hal ini dapat menjadi penyebab terhambatnya pertumbuhan janin sehingga melahirkan bayi berat lahir rendah dan bayi panjang lahir rendah (stunting). Meminjam pendapat Atmarita (2018), proses terjadinya stunting dimulai dari pra konsepsi, ketika scorang remaja menjadi ibu kurang gizi dan anemia, menjadi parah ketika hamil dengan asupan gizi tidak mencukupi kebutuhan, ditambah hidup di lingkungan dengan sanitasi kurang memadai. Ibu balita stunting saat bersalin dan masa nifas sebagian besar sudah memanfaatkan dan mendapatkan pelayanan kesehalan yang sesuai namun kurang optimal, hal ini dapat mempengaruhi kesehatannya karena kurang terpantau olch tenaga keschatan. Status gizi dan kesehatan ibu hamil yang optimal akan melahirkan bayi yang sehat.

\section{PENUTUP}

\section{Kesimpulan}

Stunting pada balita di Desa Terong Kecamatan Dlingo Kabupaten Bantul dengan prevalensi 12,54 persen banyak terjadi pada anak usia 24 bulan ke atas yang berarti sudah melewati periode 1000 HPK. Pertumbuhan status gizi semua balita stunting cenderung semakin menurun sejak awal lahir hingga saat ini dapat menjadi gambaran bahwa intervensi yang dilakukan selama ini belum bisa meningkatkan status gizi balita. Pemantauan status gizi balita yang dilakukan rutin setiap bulan oleh kader di Posyandu tidak dapat mengidentilikasi kejadian stunting pada balila.

Upaya peneegahan dan penanggulangan masalah stunting pada balita di Desa Terong 
belum optimal dan difokuskan pada masalah stunting. Demikian juga dengan pelayanan kesehatan kepada ibu dan anak yang belum sesuai target. Sebagian besar ibu hamil tidak mendapatkan pemberian makanan tambahan (PMT), ibu bersalin dan nifas serta bayi neonatus hanya memeriksakan keschatan satu kali, anak balita tidak mendapatkan ASI eksklusif, pemberian makanan tambahan (PMT), dan fortifikasi zat besi atau suplemen lainnya.

\section{Saran}

Berdasarkan hasil dan pembahasan serta kesimpulan di atas maka saran atau rekomendasi yang dapat diberikan antara lain:

1. Masalah siuning di Indonesia tidak bisa hanya diselesaikan oleh sektor kesehatan. Harus ada intervensi secara holistik dan terintegrasi. Salah satunya dengan mengoptimalkan dana desa untuk mengurangi kemiskinan di desa.

2. Harus ada kolaborasi dengan pemerintah pusal, Provinsi DI Yogyakarla, lembaga pendidikan, kelompok masyarakat, dunia usaha, dan pemangku kepentingan lainnya dalam upaya menurunkan angka stunting. Demikian pula dengan sektor pendidikan, pertanian, hingga industri juga harus ikut mengatasi persoalan ini.

3. Upaya pencegahan stunting termasuk gizi kurang harus focus pada $1000 \mathrm{HPK}$ melalui pemenuhan kebutuhan gizi dan monitoring pertambahan berat badan ibu hamil, asupan gizi selelah lahir, kewajiban pemberian ASI Eksklusif kepada bayi, dan pemberian MPASI secara optimal sesuai panduan pemberian makan bayi dan anak (PMBA).

4. Mencegah masalah stunting juga perlu penguatan sistem agar 1000 HPK dapat menjadi bagian dari budaya dan kehidupan sosial di masyarakat. Kelas ibu hamil yang dibuka pasca ditetapkannya Desa Terong sebagai lokus stunting membuka jalan untuk menyebarkan informasi tentang ASI eksklusif. Bayi yang lahir sehat harus dirawat melalui pemberian ASI eksklusif, pola asuh sehat dengan memberikan imunisasi lengkap, mendapatkan makanan pendamping ASI (MPASI) yang berkualitas dengan kuantitas yang cukup dan periode yang tepat. Langkah-langkah diatas akan menghasilkan bayi yang tumbuh optimal sehingga menghindarkan bayi dari ancaman stunting.

5. Upaya mengatasi masalah stunting pada balita dapat dilakukan dengan intervensi gizi spesifik saat memberikan pclayanan kesehatan pada ibu menyusui dan anak usia 0-6 bulan dengan kegiatan mendorong pemberian ASI Eksklusif. Pada Ibu menyusui dan anak usia 7-23 bulan intervensi dapat dilakukan dengan kegiatan mendorong meneruskan pemberian ASI hingga anak usia 23 bulan, pemberian makanan pendamping ASI, menyediakan obat cacing, menyediakan suplemen zink, melakukan fortifikasi zat besi dalam makanan, memberikan perlindungan terhadap malaria, memberikan imunisasi lengkap, melakukan pencegahan dan pengobatan diare.

6. Untuk upaya deteksi dini stunting, Kader Posyandu atau petugas pelayan kesehatan dalam melaksanakan kegiatan pemantauan status gizi balita tidak hanya menimbang berat badan saja tetapi harus mengukur tinggi badan juga. Hasil pemantauan status gizi harus segera dianalisis kesesuainnya terhadap standar kenaikan berat badan atau tinggi badan minimal. Hasil analisis ini harus digunakan sebagai dasar atau acuan intervensi tindak lanjut dalam memberikan informasi, menyuluh, melakukan konseling gizi dan keschatan, serta memberi makanan tambahan balita.

\section{DAFTAR PUSTAKA}

\section{Buku}

Aryastami, NK. 2015. Pertumbuhan Lsia Dini Menentukan Pertumbuhan Usia Pra Pubertas (Studi Langitudinal IFLS 19931997-2000). Disertasi. Program Studi Doktor IKM FKM UI. Depok.

Atmarita. 2018. Asupan Gizi Yang Optimal Untuk Mencegah Stunting, PERSAGI \& APKГSI. Buletin Jendela Data dan Informasi Kesehaian. Sm I, $2018 \mathrm{hlm} 14$ 25. 
Kemenkes RI. 2018. Balita Pendek (Stunting) di Indonesia. Buletin Jendela Data dan Informasi Keschatan. ISSN $21088-27() \times<$ semester I, 2018, Pusdatin, hlm. 2

Direktorat Kesehatan dan Gizi Masyarakat dan Sekretariat Pereepatan Perbaikan GiziBappenas. Pencegahan Stunting dan Pembangunan SDM. Buletin Jendela Data dan Informasi Kesehatan. Semester I tahun 2018. ISSN $2088-270 \mathrm{X}$. HIm : $32-38$

Izwardy, Doddy. 2016. Kebijakan dan Program Gizi Masyarakat Indonesia: Ilmu Gizi: Teori dan Aplikasi. Jakarta : ECG

Kemenko Bidang Pembangunan Manusia \& Kebudlayaan RI. 2018. Penanganan Stunting Terintegrasi di Indonesia. Jakarta: Deputi Bidang Koordinasi Peningkatan Kesehatan

Riset Kesehatan Dasar 2018

Saputra, Wiko dan Nurrizka, RH. Faklor Demografi dan Risiko Gizi Buruk dan Gizi Kurang. Makara Kesehatan Vo.16: (2). Desember 2012. Hlm : 95-101

Sugiantono, Anung. 2018. Cegah Stunting, Bersama keluarga Kita Jaga l000 Hari pertama Kehidupan. Jakarta: Biro Komunikasi dan pelayanan Masyarakat Kemenkes RI

\section{$\underline{\text { Website }}$}

Aryastami, NK dan Tarigan, Ingan. 2017. Kajian Kebijakan dan Penanggulangan Masalah Gizi Stunting di Indonesia. Butetin Penelitian Kesehatan. Vol.45, No.4. Desember 2017:233 - 240. Online. (http//dx.dui.urg/org/10.22435/bpk.v45i4.2 33-240)

Izwardy, Doddy. Februari 2019. Kebijakan dan Strategi Penanggulangan Stunting di Indonesia, Online. (https:/Www.persi.or.id)

\section{Pedoman dan Peraturan}

Undang-Undang Nomor 23 Tahun 2002 tentang Perlindungan Anak

Perpres RI. Nomor 42 Tahun 2013 tentang Gerakan Nasional Percepatan Perbaikan
Gizi tanggal 24 Mei 2013. Lembaran Negara RI. Tahun 2013 Nomor 100 tanggal 29 Mei 2013.

Peraturan Menteri Kesehatan Nomor 97 Tahun 2014 tentang Pelayanan Kesehatan Masa Scbelum Hamil, Masa Hamil, Persalinan, dan Masa Sesudah Melahirkan

Nomor 25 Tahun

2014 tentang Upaya Kesehatan Anak

Kementerian Desa Pembanguman Daerah Tertinggal dan Transmigrasi RI. 2017. Buku Saku Desa Dalam Penanganan Stronting. Jakarta.

Kementerian Perencanaan dan Pembangunan Nasionali Badan Perencanaan dan Pembangunan Nasional. Pedoman Pelaksanaan Intervensi Penurunan Stunting Terintegrasi di Kabupaten/Kota. Edisi November 2018.

Kementerian Kesehatan RI. 2019. Pedoman Pencegahan Gizi Buruk pada Balita. Jakarta.

Direktorat Bina Gizi Ditjen Bina Gizi \& KIA Kemenkes RI. 2011. Petunjuk Teknis Tatalaksana Anak Gizi Buntk. Edisi Revisi. Jakarta

Departemen Keschatan. 2001. Strategi Nasional Peningkatan P'emberian ASI Tahun 20012005. Workshop Peningkatan Pemberian ASI. Jakarta 8-10 Juli 2001

Rencana Kegiatan Anggaran (RKA) Puskesmas Dlingo Il Tahun 2019 
